\title{
217. Ultrastructure of the Pteridine Pigment Granules of the Larval Xanthophore and Leucophore in Oryzias latipes (Teleostean Fish)
}

\author{
By Ikuo Kamei-TaKeuchi, Goro Eguchi, and Tadao Hama \\ Biological Institute, Faculty of Science, Nagoya University, Nagoya
}

(Comm. by Yô K. OKadA, M.J.A., Nov. 12, 1968)

The larval xanthophore of the medaka (Oryzias latipes) is filled with yellow granules which contain sepiapterin, viz. sepiapterinosomes, and the larval leucophore, that is, erythropterinophore with brick-red granules which contain drosopterin, viz. drosopterinosome.1) As in the melanosome of melanophore, ${ }^{2)}$ sepia- and drosopterinosome have been demonstrated to be a first sign of morphological basis at the onset of xantho- and leucophore differentiation respectively.1) Although some papers have been reported on the ultrastructure of the pigment granules of chromatophores at adult stage, ${ }^{3)}$ there are some differences between the pigment granules of adult and larval stages (unpublished). This paper is to clarify the ultrastructural difference between the sepia- and drosopterinosomes at the larval stage of respective xantho- and leucophore.

Materials and methods. The larvae after hatch (ca. 5.0-6.0 $\mathrm{mm}$ ) of wild strain of Oryzias latipes were used. The submicroscopic procedures are as follows: specimens were doubly fixed with $2 \%$ glutaraldehyde and $1 \% \quad \mathrm{OsO}_{4}$ (pH 7.2-7.3, one hour for each fixative at $4^{\circ} \mathrm{C}$ ), and embedded in epoxy resin after Luft;4) staining with uranyl acetate after Watson ${ }^{4)}$ and lead citrate after Reynolds ; ${ }^{4)}$ photomicrographs were taken on a JEM T-6 electron microscope at instrumental magnification of 2,000 to 15,000 . Special attention was taken for the submicroscopic identification of chromatophores, e.g. the mutual location of chro-

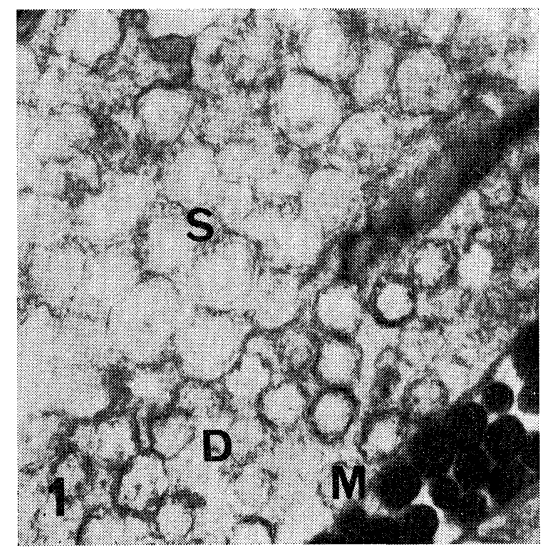

Fig. 1. Mutual position and pigment granules of larval chromatophores. The left upper corner is the outer part of skin. The sepiapterinosomes (S) of xanthophore are the largest. The drosopterinosomes (D) of leucophore are intermediate in size. The melanosomes (M) are the smallest. $\times 10,000$. 


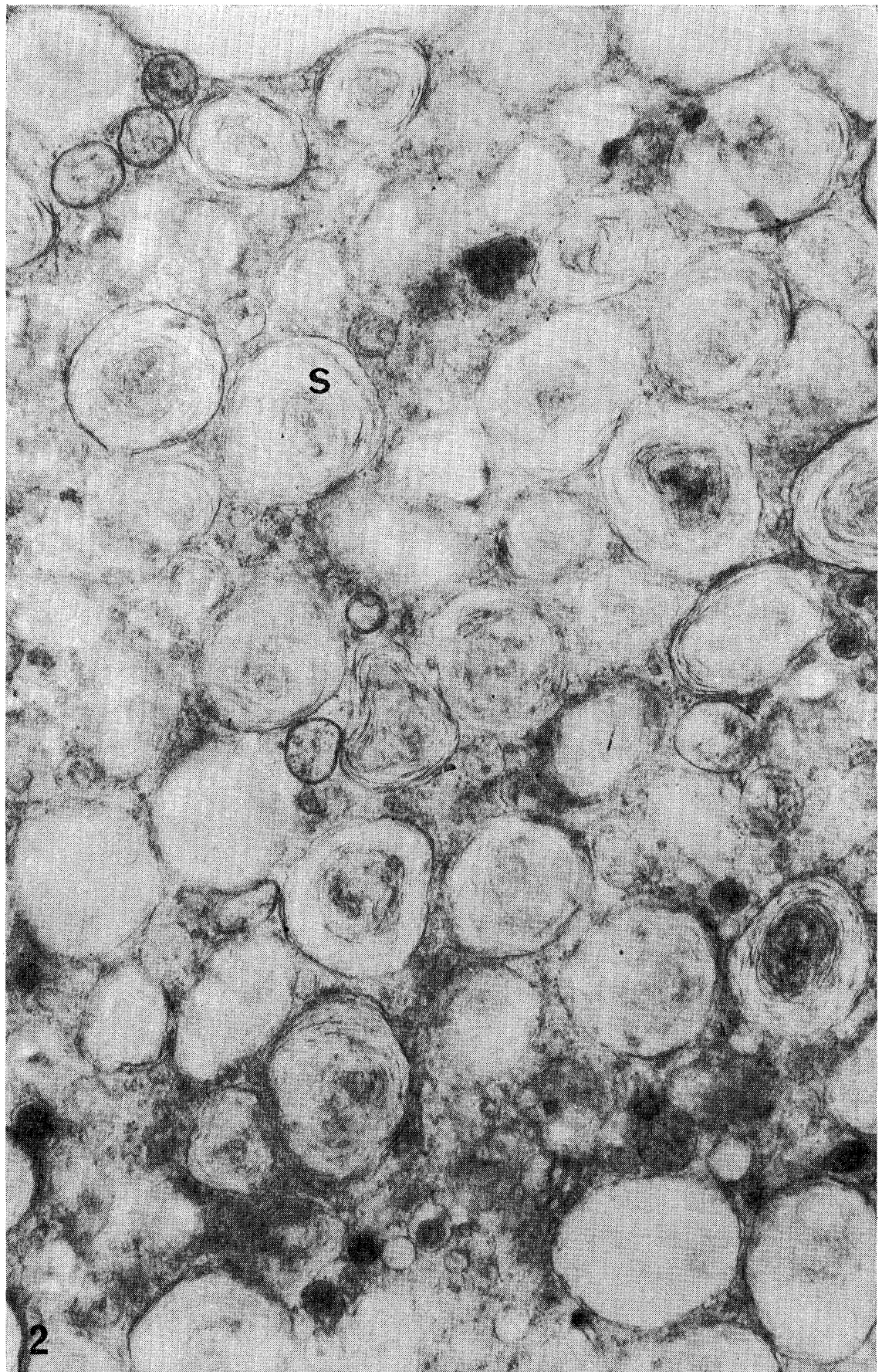

Fig. 2. The larval xanthophore is filled with different types of sepiapterinosomes (S) and interspersed with small granules or vesicles, some of which are of electron dense suggestive of lipids. $\times 24,000$. 
matophores, the lack of lipid droplets in leucophore or certain skin portion lacking leucophore etc. A decisive proof, however, was a fact that melamine substance caused the degradation of drosopterinosomes of living animal without any effect on the sepiapterinosomes (unpublished).

Results. 1. Xanthophore (Figs. 2 and 3). The typical feature of granule at this stage was ellipsoidal in shape $(0.8-1.2 \mu$ long and $0.7-0.9 \mu$ in diameter). At a glance of electron micrograph,

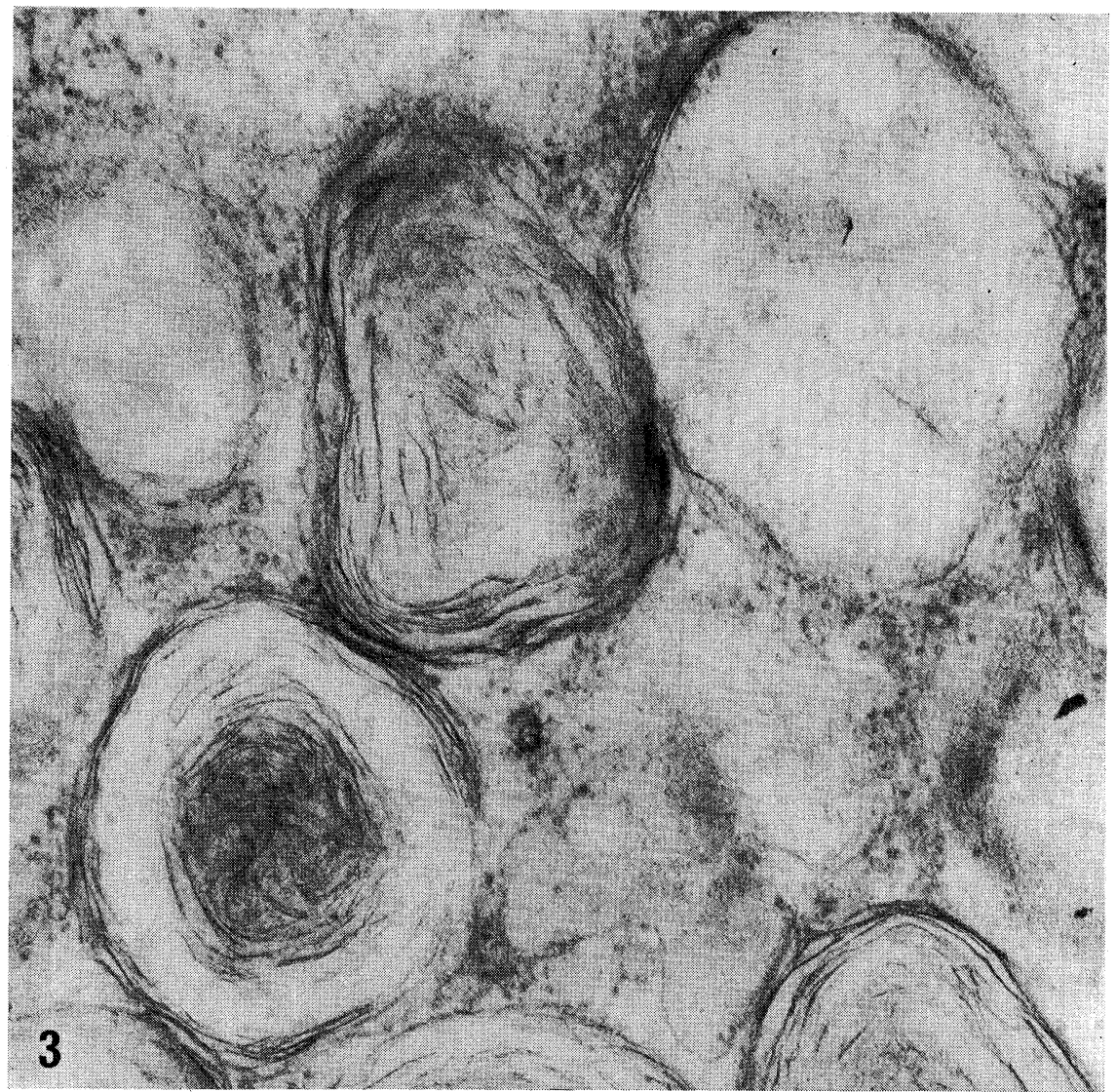

Fig. 3. Enlarged view of different types of sepiapterinosomes. Note abundant ribosome-like granules. $\times 45,000$.

different types of granules were contained in the same xanthophore. These granules can be characterized from their ultrastructures; their cortical part consisted of lamellar structure without any clear limiting membrane and their internal features were characterized with randomly oriented fibrous aggregate at different grade or with amorphous material of fibrous nature. Judging from the suggestive 


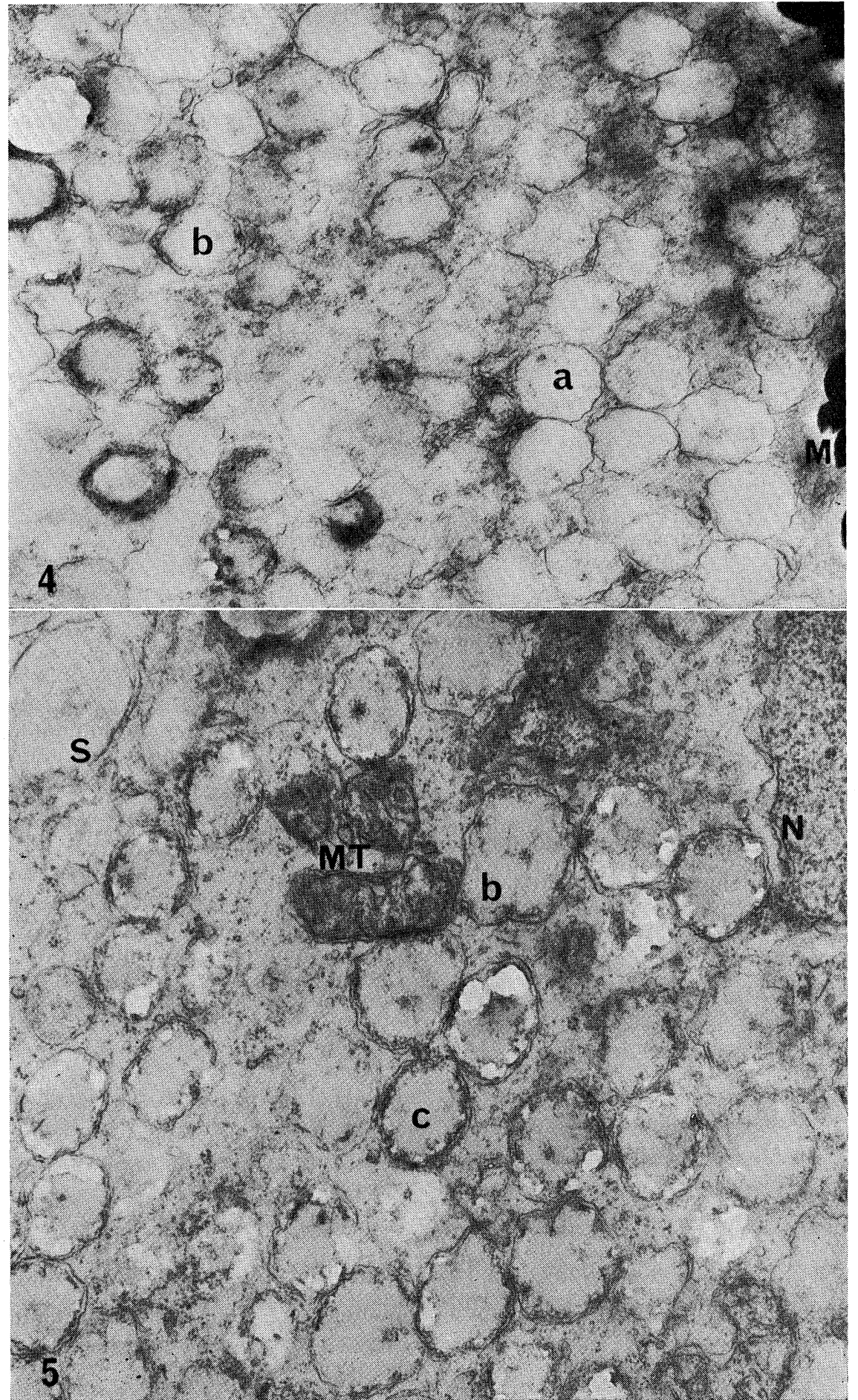

Figs. 4 and 5 
features of the transformation of amorphous or fibrous aggregates into the superficial lamellar orientation, the granule with least lamellae appeared to indicate an early phase of granule differentiation. This view remains to be confirmed. In addition to the just mentioned granules which was filled in the cell, various kinds of smaller granules or vesicles were interspersed, some of which were of electron dense suggestive of lipids.

2. Leucophore (Figs. 4 and 5). The drosopterinosomes were divided into about three types. These were found in the same cell apart from the quantitative relation among them. The granules were supposed to be transitional forms of one kind of granule from Type a to Type c. Type a granule $(0.5-0.6 \mu$ in diameter) was of a single membrane. Type b granule was limitted with double membrane, the inner one of which was suggestive of a lamella which might be resulted from the internal fiber-like structures. Type c granule $(0.7-0.8 \mu$ in diameter) was of densely stained double membrane with an intervening space and some features showed superficially located small empty spaces where the epoxy resin was presumably not infiltrated. The features in which the empty space occupied most part of granule were rather frequently obtained. The empty space as such may be caused by purine-like substances as the presence of guanine within the iridophore may be the case.

\section{References}

1) T. Hama: Ann. N. Y. Acad. Sci., 100, 977 (1963) and Compt. Ren. Soc. Biol., 161, 1197 (1967); T. Hama and H. Hasegawa: Proc. Japan Acad., 18, 901 (1967); T. Hama, T. Goto, Y. Tohnoki, and Y. Hiyama: Proc. Japan Acad., 18, 901 (1967); T. Hama, T. Goto, Y. Tohnoki, and Y. Hiyama: Proc. Japan Acad., 41, 305 (1965).

2) M. Seiji, K. Shimao, M. S. C. Birbeck, and T. B. Fitzpatrick: Ann. N. Y. Acad. Sci., 100, 497 (1963).

3) T. Hama and S. Fukuda: Pteridine Chemistry (Pergamon Press), 495 (1964); S. Kawaguchi, Y. Kamishima, and K. Sato: Biol. Jour. Okayama Univ., 11, 97 (1965); A. V. Loud and Y. Mishima: J. Cell. Biol., 18, 181 (1963); J. Matsumoto: J. Cell. Biol., 27, 493 (1965).

4) J. H. Luft: J. Biophy. Biochem. Cytol., 9, 409 (1961); E. S. Reynolds: J. Cell Biol., 17, 208 (1963); M. L. Watson: J. Biophy. Biochem. Cytol., 4, 475 (1958).

Fig. 4. Different types of drosopterinosomes in the larval leucophore. Abundant Type a granules (a) and small number of Type b granules (b) are shown together with melanosomes $(\mathrm{M}) . \times 18,000$.

Fig. 5. Different types of drosopterinosomes in the larval leucophore. Small number of Type b granules (b) and abundant Type c granules (c) are shown together with mitochondria (MT) and nucleus (N) in the same cell. Note large sepiapterinosomes (S) on the left upper corner, small drosopterinosomes and abundant ribosome-like granules. $\times 24,000$. 